\title{
Behavioural Water Safety and Autism: a Systematic Review of Interventions
}

\author{
Catriona Martin ${ }^{1} \cdot$ Karola Dillenburger $^{1}$ (D)
}

Received: 4 August 2018 / Accepted: 21 February 2019 / Published online: 8 March 2019

(C) The Author(s) 2019

\begin{abstract}
People with autism are approximately twice as likely to die from drowning than members of the general population. Drowning can take place in quite small bodies of water. Therefore, acquiring good water safety skills is of the utmost importance. A systematic review of research into effective behavioural interventions for water safety and swim skills was conducted. In total, 11 studies were identified. Findings suggest that behaviourally based interventions can improve a range of water safety and swim skills in individuals with autism.
\end{abstract}

Keywords Autism · Applied behaviour analysis · Water safety $\cdot$ Elopement $\cdot$ Drowning $\cdot$ Death $\cdot$ Systematic review

The prevalence of autism is on the rise (i.e. $2-3.5 \%$ of children are diagnosed with autism (CDC, 2013; Dillenburger et al. 2015). While the reasons for this increase are still widely debated (Waterhouse 2013), it is apparent that the overall life expectancy of people with autism is lower than the general population (Johnston 2016; Young et al. 2016).

Nearly half (49\%) of all autistic children elope and thus become subject to unsupervised dangers. Nearly a quarter (24\%) of these children are exposed to situations of 'neardrowning', with significant risks posed by even small bodies of water, such as private pools, ponds and bath tubs (Kemp and Sibert 1994). In fact, children and adults with autism are approximately twice as likely to die from drowning as members of the general population (Schendel et al. 2016), and therefore, it is particularly important that water-safety behaviours are taught to this population.

Safety skills have been defined as 'preventative or reactionary verbal or non-verbal behaviours that establish or maintain the safety of a person' (Akmanoglu and Tekin-Iftar 2011, pg. 205). Preventative safety skills need to occur before the dangerous situations in order to avoid harm (Clees and Gast 1994), for example, an important water safety skill would be to walk and not run near a swimming pool. Reactionary safety

Karola Dillenburger

k.dillenburger@qub.ac.uk

1 Centre for Behaviour Analysis, Queen's University Belfast, 69 University Street, Belfast BT71HL, Northern Ireland behaviours occur as a response to a dangerous situation to which the person is exposed (Clees and Gast 1994). Reactionary safety behaviours usually are more reflexive in nature, for example, a child holding their breath while submerged underwater.

In the context of swimming and water safety, a mixture of both preventative and reactionary skills is necessary. Preventative water safety skills include appropriate entering and exiting of the pool, as well as the proper use of flotation devices. Reactionary water safety skills include being able to surface after submersion or knowing how to reach the hand rail the side of the pool. Most swim skills are also safety skills, including re-emerging from the water after submersion, floating on the water and being able to engage in various swim strokes that allow the person to remain above water or reach safety. However, some water safety skills are more general, not directly related swim skills, for example 'staying with an adult' or not to running on a slippery surface near the water.

Given that the scientific discipline of applied behaviour analysis has developed a range of evidence-based interventions (Surgeon General 1999; York State Department of Health, 2011) that have become the 'gold standard' for autism interventions (Larsson 2013), a systematic literature review was conducted that focussed on behaviour analytic interventions for improving the aquatic safety repertoires of children diagnosed with autism.

For the purpose of this review, the definition of aquatic/ water safety repertoires included all behaviours that directly contribute to safety around water, such as swim strokes, 
submersion and recovery, or entry and exit of the pool. This review did not include skills with indirect benefits, such as communication, social interaction or 'water play'.

A Preferred Reporting Items for Systematic Reviews and Meta-Analyses model (Moher et al. 2009) was used to report search results and reasons for exclusion.

\section{Literature Search and Screening}

The following search terms were used:

1. "autism or ASD or autism spectrum disorder" and "swim*" and *aba or applied behaviour analysis".

2. "autism or ASD or autism spectrum disorder" and "swimming therapy".

3. "autism or ASD or autism spectrum disorder" and "aquatic".

The following data bases were searched: Academic Search Complete, Child Development \& Adolescent Studies, CINAHL Plus, Education Abstracts (H.W. Wilson), ERICEducation Resource Information Centre, Medline or Scopus.

Studies meeting the following criteria were included:

- Study designs: Group studies and single case studies. Purely qualitative studies were excluded.

- Participants: Individuals aged under 18 years of age with a primary diagnosis of autism spectrum disorder (ASD).

- Intervention: Water safety interventions explicitly based on applied behaviour analysis.

- Dates: Papers published between 1990 and 2018.

A total of 12 papers were identified initially. A search of the reference sections of these papers yielded another 11 possible studies (total $n=23$ ). All the titles and abstracts of these papers were reviewed. One paper was excluded due to duplication and one paper (Dulcy 1992) was excluded because the journal in which it was published (National Aquatics Journal) had been decommissioned and could not be located, despite considerable efforts including interlibrary loan requests from the British Library. Three studies were rejected as they did not address swim skills, and a further three studies were excluded because they focused on other outcomes, including social and communication interactions and physical fitness.

A total of 15 papers remained. Full-text analysis revealed that 4 studies did not use behavioural methods to teach swim skills, they used sensory integration approaches and physical therapy. Therefore, these papers were excluded. The remaining, 11 papers were included in the final review (see Fig. 1).

\section{Detailed Description of Studies}

The earliest study with a focus on water safety and swim skills in autism that explicitly based their intervention on applied behaviour analysis was Yilmaz, Yanardag, Birkan, and Bumin (Yilmaz et al. 2004), who investigated the effects of water exercise and swimming on physical fitness and observed the development of beginner swim skills in a child with autism. The target behaviours were chosen with reference to the Halliwick Method (Martin 1981) which divides key skills into four group phases: (1) adjustment to water, (2) rotations, (3) control of movement in water and (4) movement in water. This study focussed on phase 1 skills.

The Aquatic Orientation Checklist (Killian et al. 1984) was used for baseline assessment. The checklist includes four observable behaviours:

(1) walking toward pool,

(2) touching the water,

(3) water entry, and

(4) sitting or attaining a horizontal position in the water.

In addition, two beginner swim skills were measured:

(5) blow bubbles and

(6) submerge face.

The behavioural measures were defined according to level of support needed:

(a) Spontaneous: A behaviour that is observed prior to the instructor's verbal directions,

(b) Voluntary: A behaviour showing the subject's compliance with the instructor's verbal directions,

(c) Demonstration: Instructor uses verbal and visual cues to describe a specific task,

(d) Manipulation: Instructor puts subject's body through a movement which corresponds to a desired task, and manipulation is accompanied by verbal and visual cues, and

(e) Objection: Avoidance of task by absolute non-compliance, tantrum, or active resistance (i.e. pulling away, crying, shouting).

Baseline assessment showed that five out of six behaviours occurred at the level of (b) voluntary; in other words, the child engaged in the behaviours following verbal directions of the instructor; only behaviour 4 (sitting or attaining a horizontal position in the water) functioned at the level of (c) demonstration and required prompting.

The programme lasted for 10 weeks, consisting of three 60min swim sessions per week. Specific methods of teaching were not detailed in the paper. Post-intervention assessment showed that the child engaged in all six target behaviours at 
Fig. 1 Prisma chart

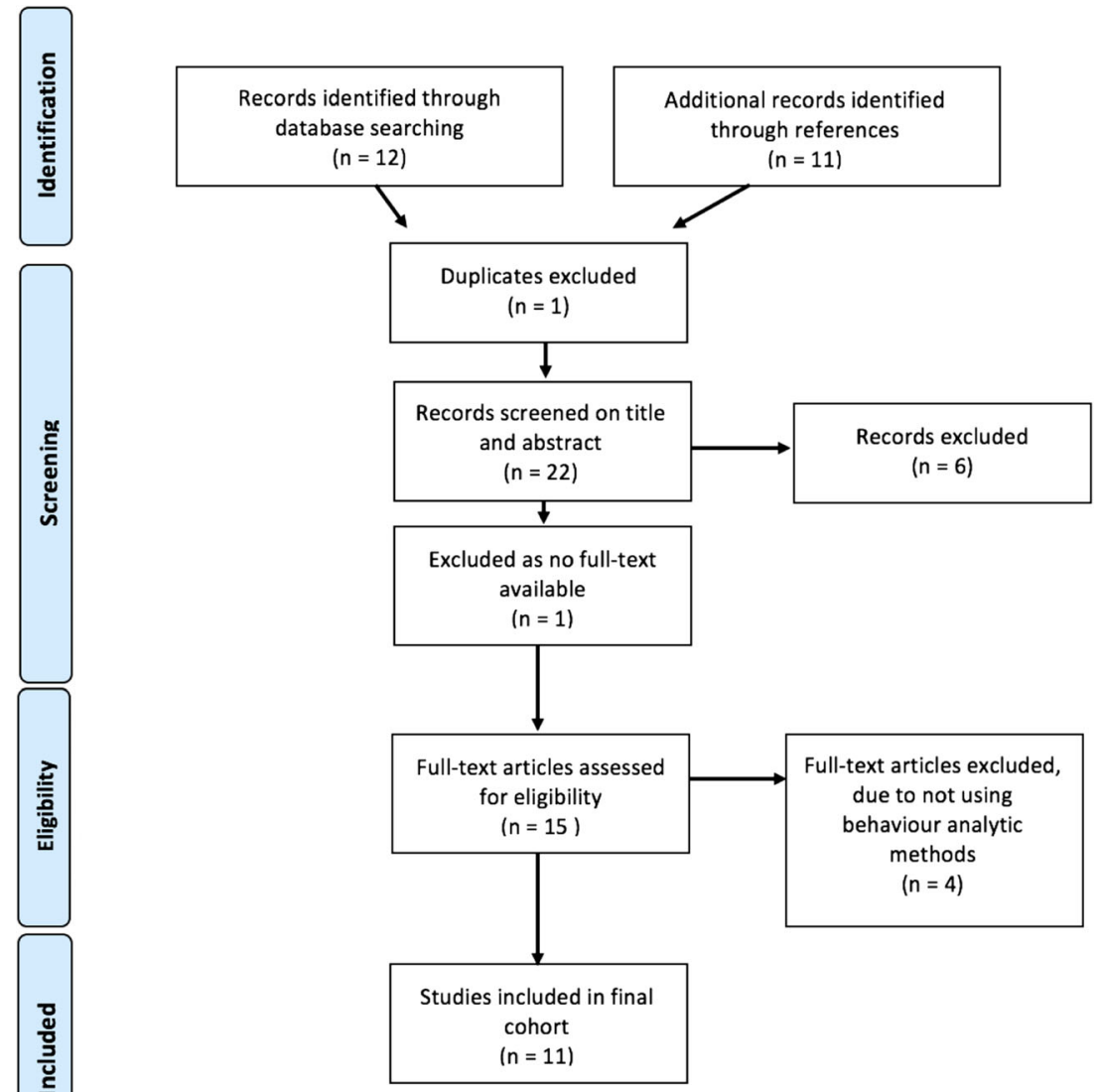

level (a) spontaneous, in other words, the child engaged in these behaviours prior to the verbal directions of the instructor. Additionally, a reduction in stereotypic behaviours, such as rocking, spinning and delayed echolalia, was reported.

Whilst this paper added to the growing body of evidence that individuals with autism can benefit from swimming and physical exercise (Aleksandrovic et al. 2015; Kuhfuss 2010; Pan 2010), there were methodological problems such as lack of stable baseline and it remained unclear exactly which independent variables were responsible for the observed behaviour change.

Huettig and Darden-Melton (2004) assessed aquatic skills in four children with autism between 7 and 13 years of age. They used the Texas Woman's University Aquatic Skills Assessment (Huettig 1998) to address

(1) water adjustment skills;

(2) flotation skills;

(3) basic propulsion and breathing skills;

(4) swimming stroke skills; and

(5) entry and exit skills.

The instruction programme targeted these skills in hierarchical order from (1) through to (5). While the paper mentioned the 'Armbruster' method (Armbruster et al. 1968), which uses the 'dog paddle' to introduce swim strokes, teaching was described as tailored to individual personalities and interests. Further details of instructional methods were not provided. Skill gains were reported for all four participants across individual repertoires, particularly in (4) stroke skills, although stroke topographies were idiosyncratic, such that three of the participants developed hybrid front crawl strokes. Social validity was not mentioned specifically but positive family outcomes were implied.

Yilmaz, Konukman, Birkan, and Yanardag (Yilmaz et al. 2005) used a constant time delay procedure and a multiple probe design to teach aquatic play skills to four boys with autism between 7 and 9 years of age. The boys all attended mainstream school. Although it was unclear if they had vocal communication skills, the boys were able to respond to visual and audio stimuli for at least $10 \mathrm{~min}$ and imitate gross motor skills, they were toilet-trained, had no open wounds and were able to stand in the pool with the water up to their waist height.

The following three aquatic play skills were targeted:

(1) 'Kangaroo'; jumping like a kangaroo in the pool,

(2) 'Cycling'; move legs forward as though pedalling a bicycle, and

(3) 'Snake'; place hands on the trainer's waist and follow around the pool for a distance of $20 \mathrm{~m}$. 
The sessions were conducted on a 1:1 basis. Prior to training, baseline probes were taken during a minimum of three sessions. Aquatic play skills were then taught using either 0 -s or 4-s constant time delay intervals. Responses were coded into six possible categories: (1) correct response, (2) anticipations, (3) errors, (4) non-wait, (5) wait and (6) no response. All types of correct responses, correct anticipations and correct waits resulted in descriptive verbal praise. All incorrect responses were ignored and the task direction for the next step was provided.

All subjects met criteria after the implementation of a 4-s constant time delay, suggesting that the procedure was effective for teaching aquatic play skills to these children.

In a later study, Yilmaz et al. 2010a, 2010bagain used a constant time delay procedure (based on the Halliwick Method; Kokaridas and Lambeck 2015; Martin 1981) and a multiple-probe-across-behaviours design to teach foundational swimming skills to three boys with autism who were between 8 and 9 years of age. The boys attended mainstream schools and were able to respond to audio-visual stimuli for at least 7-10 min and imitate gross motor skills. They were continent, had no open wounds on their bodies and were able to wear both, swimming costume and cap, without removing these prematurely. Their aquatic skills included jumping, waiting, sitting, kicking and splashing in the water.

Task analyses were conducted for two skills:

(1) vertical rotation

(2) lateral rotation

Social reinforcers, including free time activities and jumping up and down in the water, were used for 'motivational purposes'. A 4-s constant time delay procedure was applied to teach rotation skills over 30 sessions ( 3 sessions a week for 10 weeks).

All three boys' skills levels reached criterion after $3 \mathrm{~h}$ and 16 min of teaching time. Maintenance data, collected 1,2 and 4 weeks after completion of the intervention, demonstrated that the skills were retained. However, the fact that the boys had significant pre-existing skills and that the two target skills had similar topography limited the study's potential impact.

In another multiple baseline across behaviour study, also employing the Halliwick framework, Yilmaz et al. (2010b) used most-to-least prompting for the acquisition of the single target behaviour: progression swimming skill.

Participants were the same three boys with autism who participated in the Yilmaz et al. (2010a) study. All three boys met the pre-requisite conditions for the Halliwick Method. They were able to

(a) to adjust to the water,

(b) to use rotation skills in the water, and

(c) to control their movement in the water.
Sessions were conducted three times a week for a period of 10 weeks. All sessions were conducted on a 1:1 basis, using research assistants. Probes were taken prior to the training (baseline) and following acquisition of target behaviours, for a minimum of three probe sessions (maintenance and generalisation).

The most-to-least prompting procedure had three stages.

Stage 1: both physical and verbal prompts were provided. Stage 2: verbal and gestural prompts were provided.

Stage 3: verbal cues were provided.

All three participants required nine training sessions to reach criterion, i.e. progression swimming skill improved significantly during the intervention phase. In addition, these skills were maintained during 1-, 2- and 4-week generalisation phases.

A multiple probe design also was used by Rogers et al. (2010a, 2010b) to assess the effect of a constant time delay procedure on acquisition of foundational swim skills. The study was conducted by a graduate student who was trained as life guards. Participants were three boys aged 4-5 years of age, who had a diagnosis of autism, were verbal and attended an inclusive childhood education programme. The boys had gross motor skills required to perform the functional swimming skills, were not able to perform the target behaviours correctly, had no fear of the water and were able enter the pool to the depth of child's own waist independently or with limited assistance.

Instructional sessions took place two or three times per week and lasted between $45 \mathrm{~min}$ and $1 \mathrm{~h}$. Three behaviours were targeted:

(1) flutter kicking,

(2) front crawl stroke, and

(3) turning head from side-to-side (pre-requisite for rotary breathing).

An intricate recording system was devised using different coloured hairbands worn on the wrists of the instructor and moved into sequence depending on correct or incorrect responses. The instructor then transferred these raw data onto a data collection sheet after the session was completed. Mastery criterion was set at $100 \%$ correct unprompted responding across three sessions. All three participants reached the mastery criterion in 6-8 sessions.

Pan (2010) conducted a controlled, single blinded study across two groups to assess the effect of a specially designed water exercise swimming programme (WESP) on the aquatic skills and social behaviours of 16 boys with autism, aged between 6 and 9 years. The boys attended mainstream school and were able to follow instructions. None of the boys had a co-occurring intellectual disability and their current therapy or activity programmes remained unchanged. 
The study lasted 20 weeks, using a within-participant repeated measures design. Phase 1 was conducted during the first 10 weeks, when eight of the boys (group 1) took part in the WESP, while the other eight boys (group 2) engaged in other regular activity. In phase 2, during a further 10 weeks, group 2 took part in WESP and group 1 took part in other regular activity. Each participant was assessed on three occasions:

Time 1: at study entry,

Time 2: after 10 weeks of WESP (group 1) or regular activity (group 2), and.

Time 3: after a further 10 weeks of regular activity (group 1) or WESP (group 2).

Four WESP, trained research assistants took part in the study and each assistant was paired with the same two students across all sessions. Based on the Halliwick model, the Humphries Assessment of Aquatic Readiness (HAAR: Humphries 2008) was used to measure progress. Teaching included the use of clear boundaries within the pool area, visual schedules/work systems and end-of-session games. The content of each session and the pace of instruction was determined by each child's need and progress as determined by the assistant. Social behaviours were rated by the child's school teacher using the School Social Behaviour Scales (SSBS-2: Merrell 2002). Teachers were blinded to group membership of each participants.

Results indicated that social behaviours and aquatic skills improved for both groups during the WESP intervention. Aquatic skill improvements were pronounced in $4 / 5$ areas of the HAAR and were maintained in group 1 during the 10 weeks following the intervention.

Chu and Pan (2012) investigated aquatic skill acquisition in 21 children with high functioning autism $(n=14)$ or Asperger's syndrome $(n=7)$ and 21 typically developing siblings or peers from similar socio-economic and cultural neighbourhoods. All individuals were healthy, aged between 7 and 12 years and able to follow instructions.

The intervention was conducted during an after-school aquatic programme provided to children with autism. The Humphries Assessment of Aquatic Readiness checklist (HAAR: Humphries 2008) was used to assess participant's skills levels at baseline and follow-up. Each child with autism took part in 16 sessions. There were three instructional groups:

(1) teacher-directed,

(2) peer/sibling-assisted, and

(3) voluntary peer/sibling support.

Peer and sibling assistants received four training sessions introducing the rules and explaining their roles, prompting techniques and social interactions. All assistants had to pass a written and practical test with a score of $90 \%$ or higher; additional training was provided until this standard was met.
While the main focus of this study was the number of interactions that occurred between the individuals with autism and the peer or sibling assistants, outcomes showed that aquatic skills increased in all participants.

A multiple probe design was used to assess the effectiveness of video prompting on the acquisition of aquatic play skills by Yanardag et al. (2013). Three children with autism ( 1 female and 2 male) met all the inclusion criteria. They had independent toileting skills and were able to follow verbal prompts, imitate motor skills, watch a video screen for at least 2 min and had no physical health conditions and no hypersensitivity to water.

The aquatic sessions were conducted by three PhD-level researchers and three exercise specialists. A video prompt was displayed on a laptop that was positioned at the side of the pool and showed each step in the task analysis of the required skill. This was shown to the participant prior to them being asked to perform the corresponding skill. Once each step had been mastered, instruction on the next step began.

Teaching occurred on a 1:1 basis. All three participants reached mastery criteria for all three target behaviours in 36 trials. Incorrect responding occurred between 8.3 and $22.2 \%$ of the time. Maintenance probes were conducted at 1,2 and 4 weeks following and showed the skills had been maintained.

Jull and Mirenda (2016) used a modified, non-concurrent multiple baseline design to assess the impact of behavioural skills training (BST) on the ability of recreation centre staff to use discrete trials and visual activity schedules to teach swimming skills to children with autism in public swim settings.

Participants included six community-based swim instructors and eight children with autism ( 7 boys and 1 girl) aged between 5 and 8 years. The individuals were verbal and seven of them had received previous swim tuition, one of whom had advanced swimming skills. The individuals had no fear or water, no severe problem behaviour and were able to tolerate physical prompting. None of the individuals had previously met the instructor in this study.

Five of the individuals received 1:1 tuition and three of them took part in group sessions. Each child participated in $5 \times 30$-min intervention sessions. Data were collected on four dependent variables:

(1) instructors' use of key skills,

(2) child compliance on first request,

(3) child swim skill acquisition, and

(4) social and ecological validity.

All skills improved for all participants.

Levy et al. (2017) targeted the acquisition of water submersion skills (a pivotal water safety skill) using a behavioural treatment package though a combined multiple baseline and changing criterion design. There were three participants, a 4year-old typically developing girl and 2 children with autism, 
aged 4 and 8 years. All three individuals had shown resistance to underwater submersion in previous swimming lessons.

The behavioural treatment package consisted of shaping and prompting procedures that were conducted in 30-min sessions, once a week over the course of a year. Sessions were conducted by a swim instructor who was also a graduate in ABA. Mastery was achieved for all three participants in 18-27 sessions. Maintenance probes were conducted 6, 12 and 24 months after completion of the programme and demonstrated that the target behaviour had been maintained and the individuals had learned more advanced swim skills including diving, jumping into the water and swimming underwater.

\section{Analysis}

The 11 studies that met all inclusion criteria were analysed across the following categories: (1) participant characteristics, (2) skills taught, (3) methods used (i.e. teaching procedures) and (4) outcomes (see Table 1)

\section{(1) Participant characteristics}

There were significant similarities between the characteristics of participants. Almost all studies selected individuals with autism who did not have a co-occurring learning disability or severe challenging behaviours. Only two studies were unclear about the level of functioning of participants (Jull and Mirenda 2016; Yilmaz et al. 2004) and two studies explicitly excluded individuals who did not have Asperger's syndrome or high-functioning autism (Chu and Pan 2012; Pan 2010).

However, the studies that did not explicitly exclude more severe forms of autism with co-occurring learning disability may have done so implicitly due to inclusion criteria, e.g. Yilmaz et al. (2010a, 2010b) required participants to be able to attend for 7-10 min and to have imitation and independent toileting skills; Jull and Mirenda (2016) only included participants who were verbal and excluded individuals with severe challenging behaviour; Chu and Pan (2012) required all participants to be able to 'follow instructions', and the participants in Levy et al. (2017) were already able to swim with or without a flotation device.

Whilst these criteria did not specifically exclude children with a dual diagnosis (autism and severe learning disability), they probably did so implicitly, as these children are more likely to engage in challenging behaviours (NICE 2015) and have additional difficulties sustaining attention (Cantwell and Baker 1991) and are less likely to have well-developed imitation skills (Ledford and Wolery 2011) and independent toileting (Cicero and Pfadt 2002). Therefore, future research would need to establish if the procedures described above could be used successfully with children with autism and cooccurring severe learning disabilities.

\section{(2) Skills taught}

The specific behaviours targeted in the studies varied. While most studies targeted multiple behaviours based on the specific needs and existing repertoires of participants (Chu and Pan 2012; Huettig and Darden-Melton 2004; Pan 2010; Yilmaz et al. 2004; Yilmaz et al. 2010a, 2010b), two studies targeted 'aquatic play skills' (Yanardag et al. 2013; Yilmaz, Birkan, Konukman, \& Erkan, Yilmaz et al. 2005). Rogers et al. (2010a, 2010b) specifically targeted flutter kicks, arms strokes and head turns, and Yilmaz et al. 2010b) targeted Halliwick's simple swimming skills (Martin 1981). Levy et al. (2017) targeted underwater submersion and was the only study that focused on the acquisition of skills for the purpose of water safety.

A number of different aquatic assessments were used to select the target behaviours. Yilmaz and Yanardag and colleagues (Yanardag et al. 2013; Yilmaz et al. 2004) referred to Halliwick's model (Martin 1981), while Pan and colleagues (Chu and Pan 2012; Pan 2010) used the Humphries Assessment of Aquatic Readiness (Humphries 2008), and Huettig (Huettig and Darden-Melton 2004) used their own Texas Woman's University Aquatic Skills Assessment (Huettig 1998). All other studies did not use pre-set curricula but instead selected individual target behaviours that were appropriate for the participants.

Despite these differences, the response classes that were targeted were relatively consist and most often included skills related to tolerating water, e.g., splashing, flotation, swim stroke, and entry and exit of the pool (Huettig 1998; Humphries 2008; Martin 1981).

Given that all studies reported achievement of targeted skills, there was no specific difference in terms of which skills would be most usefully selected for intervention.

\section{(3) Methods used (i.e. teaching procedures)}

Duration and frequency of tuition: Programme durations varied significantly across studies with some lasting only 10 weeks (Yilmaz et al. 2010a, 2010b; Yilmaz et al. 2004; Yilmaz et al. 2010a, 2010b) and others in excess of a year (Huettig and Darden-Melton 2004; Levy et al. 2017). Intensity of delivery was not always stated but appeared less variable, e.g. one study operated on 1 session per week (Levy et al. 2017) but the vast majority of interventions were delivered between 2 and 3 times per week (Chu and Pan 2012; Pan 2010; Rogers et al. 2010a, 2010b; Yanardag et al. 2013; Yilmaz et al. 2010a, 2010b; Yilmaz et al. 2004). Session length varied between 30 and 90 min for all studies. 


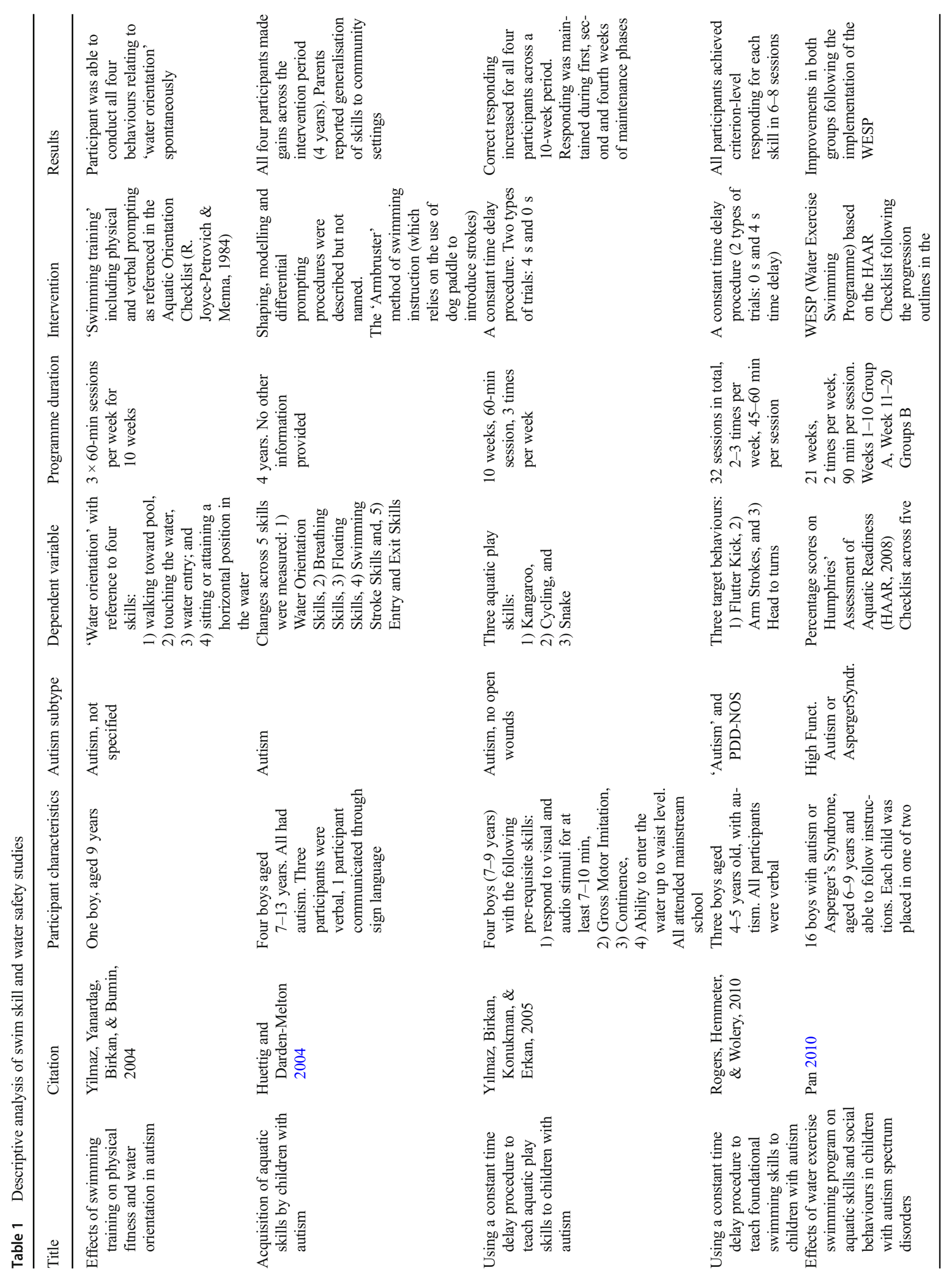




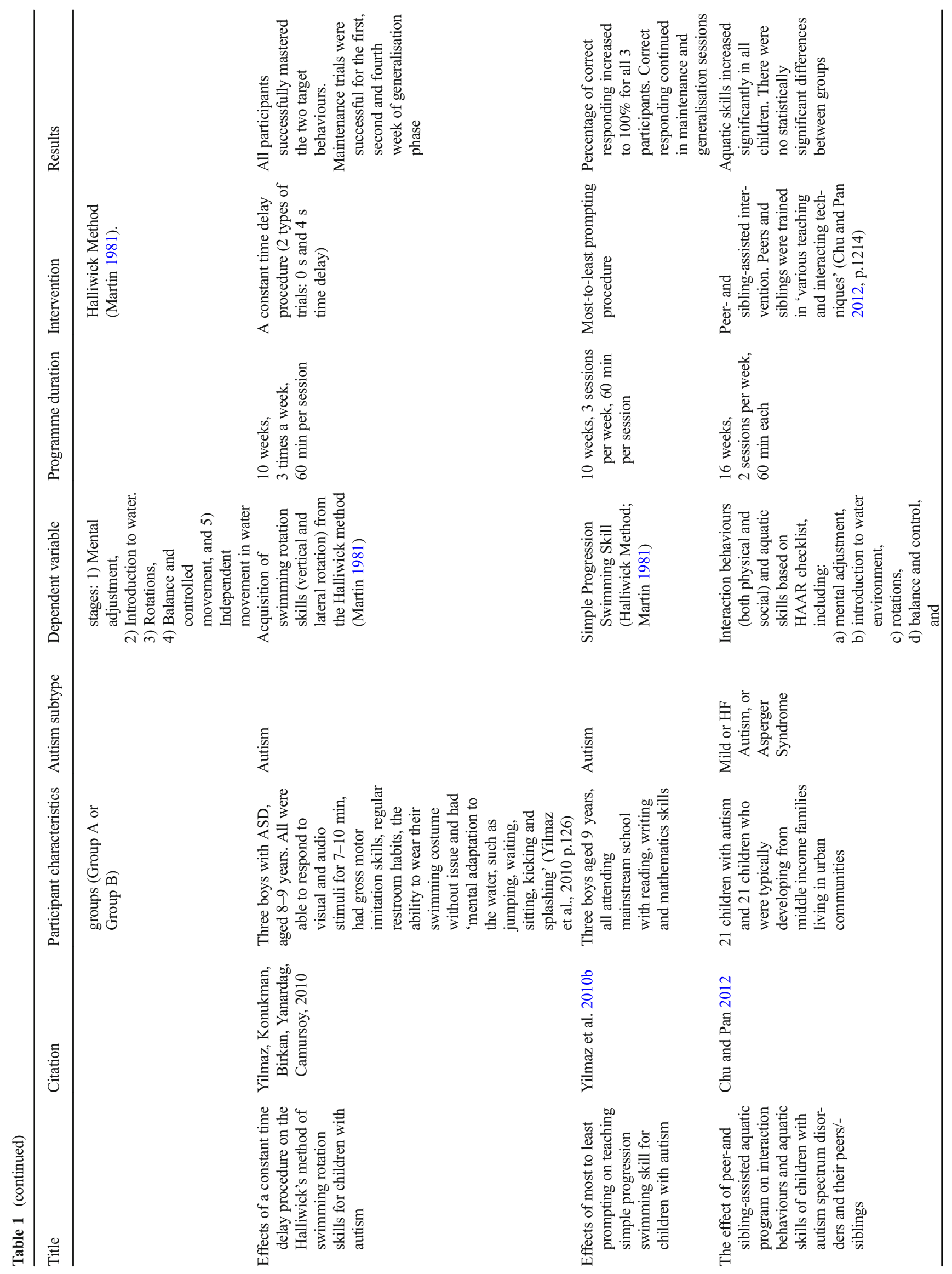




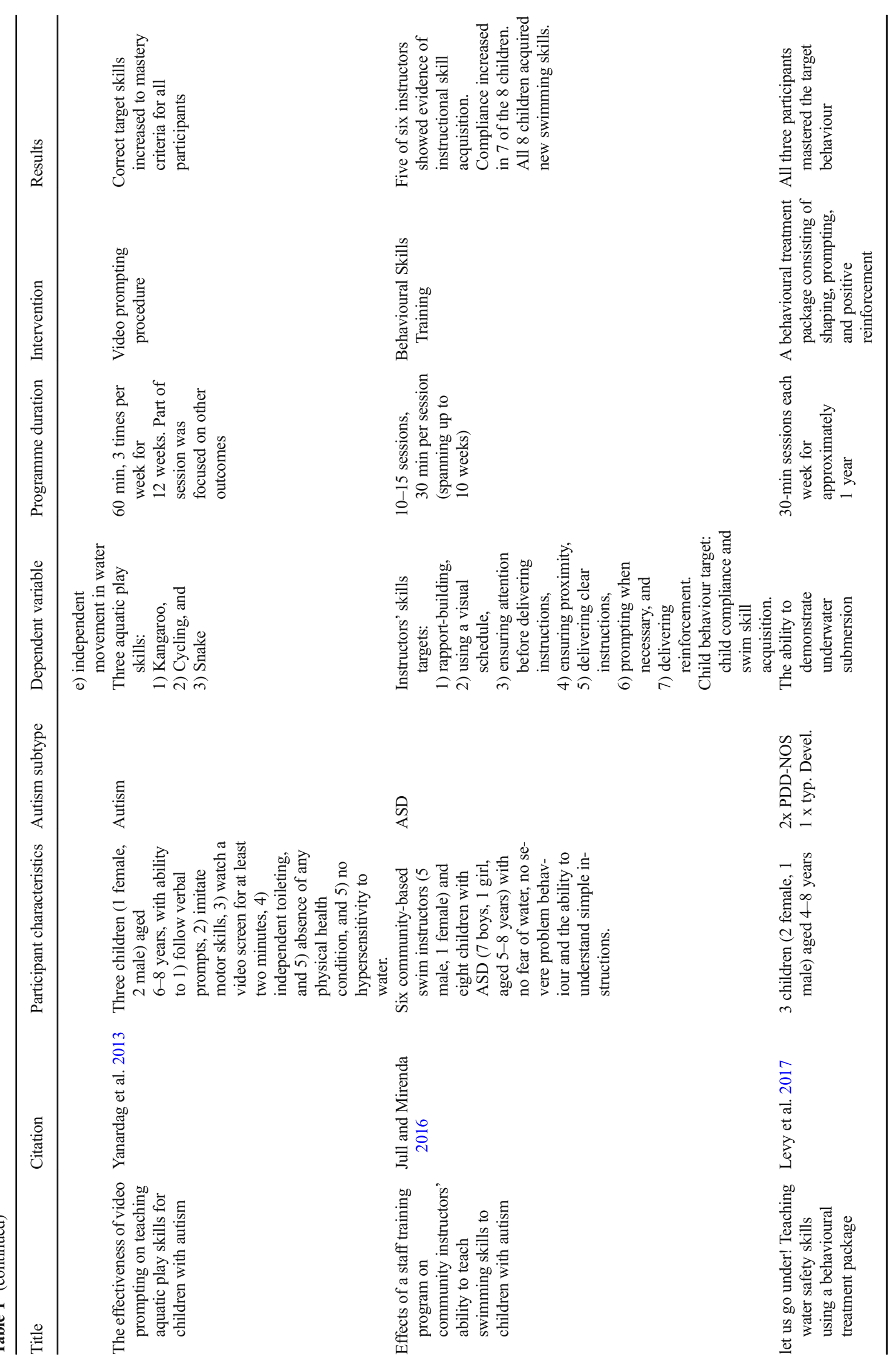


Session duration and frequency (i.e. intensity) did not seem to be related to intervention success. Future research should explore issues of treatment intensity and dose effects more carefully.

Intervention methods: While all studies used procedures that were based in applied behaviour analytic, the specifics varied across the studies. Prompting was used most often, at times alongside other techniques, e.g. Yilmaz et al. (2010a, 2010b) used most to least prompting; Levy et al. (2017) used prompting alongside a shaping procedure; Chu and Pan (2012) used prompting as part of a peer-assisted programme; and video prompting was used by Yanardag et al. (2013).

Three studies used a constant time delay procedure (Rogers et al. 2010a, 2010b; YilmazYilmaz et al. 2010a, 2010b; Yilmaz et al. 2005), Jull and Mirenda (2016) used a behavioural skills training approach and in three of the projects teaching methods were unclear (Huettig and Darden-Melton 2004; Pan 2010; Yilmaz et al. 2004);

Prompting procedures and constant time delay procedure were the only teaching methods which were used across multiple research projects; however, given that all studies report positive outcomes, there does not appear to be an obvious choice of method for teaching swim skills. Given the diversity of target behaviours, it is obvious that the teaching method needs to be individually tailored to the participant/s' preexisting skills and the behaviour/s being targeted.

\section{(4) Outcomes}

Across the 11 studies included in this review, there was a diverse range of on-deck and in-pool behaviours all of which showed improvement across time, suggesting that the methods used were appropriate for multiple types of swim skills and not just play, functional or safety skills.

\section{Conclusion}

This systematic review focuses on the use of applied behaviour analytic methods to teach swim skills and water safety to individuals with autism. The identification and screening process found 11 papers that met the inclusion criteria. However, of those 11 papers, only one concerns the issue of water safety. Positive outcomes were reported in all 11 papers, indicating that applied behaviour analytic methods can be effective in teaching individuals with autism both in-pool and on-deck behaviours.

Almost all of the studies described in this review have significant limitations, including restricted inclusion criteria for participants and narrowly defined target behaviours. The prerequisite skills required for participation usually included vocal language, being fully toilet trained and good levels of motor imitation, all skills that bias selection for higher functioning participants.
With the exception of Levy et al. (2017), none of the studies focussed on water safety and Levy et al. only focussed on a single behaviour as opposed to a curriculum of safety skills. The only other study that focussed on the social impact of swimming (Rogers et al. 2010a, 2010b) emphasised physical health benefits, reduction in self-stimulatory behaviours or increase in the use of language. Given these gaps and limitations and the vital importance of the topic, it is clear that comprehensive research is required to determine the best intervention methods to teach water safety skills to individuals with autism, specifically including those with learning disabilities or severe problem behaviour. Particular focus should be given to teaching comprehensive packages, the delivery of these packages in typical or natural teaching settings and the including of individuals with learning disabilities or other co-occurring conditions.

This review showed that behavioural analytic procedures can be successfully applied to teach swimming and water safety skills to individuals with autism with a view to reducing drowning in this population. The identification and screening process highlighted 11 papers which met the inclusion criteria. Positive outcomes were seen in all 11 research projects indicating that applied behaviour analytic methods can be effective to teach individuals with autism both in-pool and on-deck behaviours.

Acknowledgements The research was conducted in partial fulfilment of doctoral level study by the first author under the supervision of the second author.

\section{Compliance with Ethical Standards}

Conflict of Interest The authors declare that they have no conflict of interest.

Open Access This article is distributed under the terms of the Creative Commons Attribution 4.0 International License (http:// creativecommons.org/licenses/by/4.0/), which permits unrestricted use, distribution, and reproduction in any medium, provided you give appropriate credit to the original author(s) and the source, provide a link to the Creative Commons license, and indicate if changes were made.

Publisher's Note Springer Nature remains neutral with regard to jurisdictional claims in published maps and institutional affiliations.

\section{References}

Akmanoglu, N., \& Tekin-Iftar, E. (2011). Teaching children with autism how to respond to the lures of strangers. Autism, 15(2), 205-222. https://doi.org/10.1177/1362361309352180

Aleksandrovic, M., Jorgic, B., Block, M., \& Jovanovic, L. (2015). The effects of aquatic activities on physical fitness and aquatic skills in chidren with autism spectrum disorders: A systematic review. Physical Education and Sport, 13(3), 351-362.

Armbruster, D. A., Allen, R., \& Billingsley, H. S. (1968). Swimming and diving. St Louis: CV Mosby Co..

Cantwell, D. P., \& Baker, L. (1991). Association between attention deficit-hyperactivity disorder and learning disorders. Journal of 
Learning Disabilities, 24(2), 88-95. https://doi.org/10.1177/ 002221949102400205.

Centres for Diseast Control; CDC. (2013). Data and statistics, autism Spectrum disorders. Retrieved January 30, 2018, From https:// www.cdc.gov/ncbddd/autism/data.html

Chu, C. H., \& Pan, C. Y. (2012). The effect of peer- and sibling-assisted aquatic program on interaction behaviors and aquatic skills of children with autism spectrum disorders and their peers/siblings. Research in Autism Spectrum Disorders, 6(3), 1211-1223. https:// doi.org/10.1016/j.rasd.2012.02.003.

Cicero, F. R., \& Pfadt, A. (2002). Investigation of a reinforcement-based toilet training procedure for children with autism. Research in Developmental Disabilities, 23(5), 319-331. https://doi.org/10. 1016/S0891-4222(02)00136-1.

Clees, T. J., \& Gast, D. L. (1994). Social Safety Skills Instruction for Individuals with Disabilities: A Sequential Model. Education \& Treatment of Children, 17(2), 163-184.

Dillenburger, K., Jordan, J.-A., McKerr, L., \& Keenan, M. (2015). The millennium child with autism: Early childhood trajectories for health, education and economic wellbeing. Developmental Neurorehabilitation, 18(1). https://doi.org/10.3109/17518423. 2014.964378

Dulcy, F. H. (1992). An integrated developmental aquatic program (IDAP) for children with autism. National Aquatics Journal, 8(2), $7-10$.

Huettig, C. (1998). Texas Woman's University Aquatic Skills Assessment. Retrieved August 4, 2018, from https://uk.humankinetics.com/ blogs/excerpts/the-modified-twu-aquatic-assessment

Huettig, C., \& Darden-Melton, B. (2004). Acquisition of Aquatic Skills by children with autism. Palaestra, 20(2), 20-25.

Humphries, K. M. (2008). Assessment of Aquatic Readiness, unpublished master's thesis. Retrieved August 4, 2018, from https://www. yumpu.com/en/document/view/27404421/humphries-assessmentof-aquatic-readiness-haar-a-.

Johnston, I. (2016). Autism: Why do many autistic people die before the age of 40? The independent. Retrieved August 4, 2018, from https:// www.independent.co.uk/life-style/health-and-families/health-news/ autism-why-do-many-autistic-people-die-before-the-age-of-40a6937911.html

Jull, S., \& Mirenda, P. (2016). Effects of a staff training program on community instructors' ability to teach swimming skills to children with autism. Journal of Positive Behavior Interventions, 18(1), 2940. https://doi.org/10.1177/1098300715576797.

Kemp, A. M., \& Sibert, J. R. (1994). Childhood drowning. Irish Medical Journal, 3, 35-36.

Killian, K. J., Joyce-Petrovich, R. R., Menna, L., \& Arena, S. A. (1984). Measuring water orientation and beginner swim skills of autistic individuals. Adapted Physical Activity Quarterly, 1(4), 287-295.

Kokaridas, D., \& Lambeck, J. (2015). The Halliwick concept: Toward a collaborative aquatic approach. Inquiries in Sport \& Physical Education., 13(2), 65-72.

Kuhfuss, E. (2010). Rise to the Challenge: Examining the Relationship of Swimming \&amp; Autism Spectrum Disorders. Journal of the American Academy of Special Education Professionals, 16-22.

Larsson, E. V. (2013). Is applied behavior analysis (ABA) and early intensive behavioral intervention (EIBI) an effective treatment for autism? A cumulative review of impartial reports. Retrieved August 4, 2018, from http://www.behavior.org/resources/649.pdf

Ledford, J. R., \& Wolery, M. (2011). Teaching imitation to Young children with disabilities: A review of the literature. Topics in Early Childhood Special Education. Los Angeles, CA: SAGE PublicationsSage CA. https://doi.org/10.1177/0271121410363831.

Levy, K., Ainsleigh, S., \& Hunsinger-Harris, M. (2017). Let's go under! Teaching water safety skills using a behavioral treatment package. Education \& Training in Autism \& Developmental Disabilities, 52(2), 186-193.
Martin, J. (1981). The Halliwick method. Physiotherapy, 67(10), 288 291.

Merrell, K. W. (2002). School Social Behavior Scales, Second Edition. Eugene, OR: Assessment-Intervention Resources.

Moher, D., Liberati, A., Tetzlaff, J., Altman, D. G., \& Group, T. P. (2009). Preferred reporting items for systematic reviews and meta-analyses: the PRISMA statement. PLoS medicine. https://doi.org/10.1371/ journal.pmed.1000097.

NICE. (2015). Challenging behaviour and learning disabilities: Prevention and interventions for people with learning disabilities whose behaviour challenges. Retrieved June 17, 2018, from https://www.nice.org.uk/guidance/ng11

Pan, C. (2010). Effects of water exercise swimming program on aquatic skills and social behaviors in children with autism spectrum disorders. Autism, 14(1), 9-28. https://doi.org/10.1177/ 1362361309339496.

Rogers, L., Hemmeter, M. M. L., \& Wolery, M. (2010a). Using a constant time delay procedure to teach foundational swimming skills to children with autism. Topics in Early Childhood Special Education, 30(2), 102-111.

Rogers, L., Hemmeter, M., \& Wolery, M. (2010b). Using a constant time delay procedure to teach foundational swimming skills to children with autism. Topics in Early Childhood, XX0X0, 1-10. https://doi. org/10.1177/0271121410369708.

Schendel, D. E., Overgaard, M., Christensen, J., Hjort, L., Jørgensen, M., Vestergaard, M., \& Parner, E. T. (2016). Association of psychiatric and neurologic comorbidity with mortality among persons with autism spectrum disorder in a danish population. JAMA Pediatrics, 170(3), 243-250. https://doi.org/10.1001/jamapediatrics.2015. 3935.

Surgeon General. (1999). Mental health: A report of the Surgeon General. Retrieved July 28, 2018, from https://profiles.nlm.nih.gov/ps/ retrieve/ResourceMetadata/NNBBHS

Waterhouse, L. (2013). Rethinking autism. Academic Press. Elsevier Inc. https://doi.org/10.1016/C2011-0-05166-9.

Yanardag, M., Akmanoglu, N., \& Yilmaz, I. (2013). The effectiveness of video prompting on teaching aquatic play skills for children with autism. Disability and Rehabilitation, 35(1), 47-56. https://doi.org/ 10.3109/09638288.2012.687030.

Yilmaz, I., Yanardag, M., Birkan, B., Yanarda, M., Birkan, B., \& Bumin, G. (2004). Effects of swimming training on physical fitness and water orientation in autism. Pediatrics International, 46(5), 624 626. https://doi.org/10.1111/j.1442-200x.2004.01938.x.

Yilmaz, İ., Birkan, B., Konukman, F., \& Erkan, M. (2005). Using a constant time delay procedure to teach aquatic play skills to children with autism. Education and Training in Developmental Disabilities. Division on Autism and Developmental Disabilities, 40(2), 171182.

Yilmaz, I., Konukman, F., Birkan, B., Özen, A., Yanardag, M., \& Camursoy, I. (2010a). Effects of constant time delay procedure on the Halliwick's method of swimming rotation skills for children with autism. Education and Training in Autism and Developmental Disabilities, 45(1), 124-135.

Yilmaz, I., Konukman, F., Birkan, B., \& Yanardağ, M. (2010b). Effects of most to least prompting on teaching simple progression swimming skill for children with autism, 45(3), 440-448.

York State Department of Health, N. (2011). Clinical practice guidelines: Quick reference guide for parents and professionals. Autism/ pervasive development disorders. Assessment and intervention for Young children (age 0-3 years). In New York http://www.health.ny. gov/publications/4216.pdf.

Young, K., Shaw, S., Spiers, J., \& Sterry, R. (2016). Personal tragedies, public crisis. The urgent need for a national response to early death in autism. Autistica. Retrieved august 4, 2018, From https://www. autistica.org.uk/downloads/files/Personal-tragedies-public-crisisONLINE.pdf 